\title{
DESENVOLVIMENTO DA RÚCULA EM CINCO TIPOS DE ESTERCOS EM CULTIVO ORGÂNICO
}

Thadeu Henrique Novais Spósito ${ }^{1,3}$, Luis Eduardo Vieira Pinto ${ }^{2,3}$, Luciana Boulhosa Fabris ${ }^{2,3}$, Ana Lígia Garcia Nakagaki ${ }^{3}$

${ }^{1}$ Universidade Estadual Paulista - UNESP, Programa de Pós-Graduação em Agronomia, Ilha Solteira, SP. ${ }^{2}$ Universidade do Oeste Paulista - UNOESTE, Programa de Pós-Graduação em Agronomia, Presidente Prudente, SP. ${ }^{3}$ Centro Paula Souza - ETEC, Curso Técnico em Agropecuária, Presidente Prudente, SP. E-mail: thadeusposito@agronomo.eng.br

\section{RESUMO}

A produção de rúcula (Eruca sativa) com qualidade é fundamental para obtenção de cultivos com alta produtividade e rentabilidade para o produtor. O delineamento experimental foi realizado na ETEC Prof. Dr. Antônio Eufrásio de Toledo em Presidente Prudente, com seis tratamentos, utilizando adubos orgânicos provenientes da mesma, sendo um tratamento para a testemunha. As mudas de rúcula foram avaliadas após quarenta e oito dias. Os resultados obtidos permitiram concluir que o cultivo da rúcula com o esterco de coelho resultou em melhor desenvolvimento das plantas. O uso de resíduos orgânicos de fontes diversificadas na adubação tem como finalidade aumentar a produtividade sem a degradação do meio ambiente.

Palavras-chave: Eruca sativa, adubação, agricultura sustentável, produtividade, reaproveitamento.

\section{ARUGULA DEVELOPMENT IN FIVE TYPES OF ORGANIC FARMING IN MANURE}

\begin{abstract}
The production of rocket (Eruca sativa) quality is critical for obtaining crops with high production and profitability for the producer. The experiment was conducted at ETEC Prof. Dr. Antonio Eufrásio of Toledo in Presidente Prudente, with six treatments using organic fertilizers from the same, and a treatment for the witness. The arugula seedlings were evaluated after forty-eight days. The results showed that the production of arugula with rabbit manure had the best development. The use of organic waste from diverse sources such as fertilizer, aims to increase productivity without environmental degradation.
\end{abstract}

Keywords: Eruca sativa, fertilization, sustainable agriculture, productivity and reuse. 


\section{INTRODUÇÃO}

A rúcula (Eruca sativa) é uma hortaliça folhosa da família Brassicaceae, a mesma da couve, couve-flor, repolho e brócolis. As hortaliças desta família possuem substâncias importantes para a manutenção da saúde. A rúcula possui muitas propriedades medicinais, ajuda no controle de escorbuto, doenças pulmonares (asma, tosse), falta de apetite, gases intestinais, desintoxicação do organismo e anemia. Apresenta altos teores de potássio, enxofre, ferro e de vitamina A e C ; e possui sabor picante e odor agradável. Também é rica em ômega 3, ácido graxo capaz de varrer os triglicerídeos das artérias (FILGUEIRA, 2000).

Apresenta porte baixo, folhas tenras e é muito apreciada na forma de saladas. Foi introduzida no Brasil pelos imigrantes italianos, sendo mais consumida nas regiões Sul e Sudeste. Entretanto, o seu consumo é crescente em outras regiões do país (SEDIYAMA et al., 2007). Dentre as hortaliças mais comercializadas no Brasil, a rúcula ocupa a 24으 posição e entre as folhosas está no quinto lugar vindo logo após a alface, cebolinha, couve e repolho (EMBRAPA/SEBRAE, 2010).

A popularidade da rúcula como cultura é devido ao sabor picante de suas folhas, que são usadas em guarnição de saladas, petiscos e de grande variedade de pratos. A semente é utilizada como fonte de óleo na Índia e na tradicional fitoterapia, com vários propósitos (HARDER, 2004).

Recomenda-se espaçamento de 0,25 a 0,30 m entre sulcos e de 0,05 m entre plantas e desbaste quando as plantas apresentarem $0,10 \mathrm{~m}$ de altura. A colheita normalmente se dá 30 a 40 dias após a semeadura cortando-se as folhas rente ao solo, mas o mercado de alguns Estados (PR, RJ, SP, MG, dentre outros) prefere plantas inteiras, após a eliminação das folhas senescentes (MAKISHIMA, 1993).

O Estado que mais comercializa a rúcula é São Paulo, particularmente na CEAGESP. Dados levantados pelo Sistema de Informação e Estatística de Mercado da CEAGESP demonstram que a evolução do volume comercializado de rúcula neste entreposto entre 1999 e 2009 apresentou um aumento de $103 \%$, chegando a uma produção de 3.445 toneladas (ROCHA, 2010).

De acordo com a EMBRAPA/SEBRAE (2010) a rúcula produz melhor sob temperaturas amenas entre $15^{\circ}$ e $25^{\circ} \mathrm{C}$. Em regiões em que o verão é ameno, pode ser plantada durante o ano todo, porém no Nordeste, estes autores recomendam que o plantio seja realizado apenas de março a julho.

As fontes mais comuns de resíduo orgânico são representadas pelos resíduos de culturas, estercos, compostos e outros (CALEGARI, 1998). A adubação orgânica preconiza a utilização de resíduos orgânicos de origem animal, vegetal, agroindustrial e outros, com a finalidade de aumentar a produtividade das culturas sem que a propriedade perca o caminho da 
sustentabilidade ambiental, e possa caminhar no sentido da preservação dos recursos naturais, e pensar no futuro onde esses recursos serão utilizados pelas próximas gerações (SILVA, 2008).

A composição química dos estercos é variável, sendo influenciada por vários fatores, como a espécie animal, a raça, a idade, a alimentação, o material utilizado como cama, o índice de aproveitamento de nutrientes da ração pelos animais, os produtos veterinários fornecidos aos animais, além de outros. Nos materiais originários de granjas com confinamento e grande oferta de ração aos animais há uma tendência de se produzir estercos mais ricos em nutrientes. Por outro lado, estercos oriundos de produções animais em pasto apresentam mais fibras e são menos ricos em nutrientes. Em relação aos animais adultos, os jovens aproveitam melhor o alimento fornecido e isto implica em estercos com menor reserva de nutrientes (TEDESCO et al., 2008).

O mercado de produtos orgânicos vem crescendo graças à preocupação de consumidores com uma alimentação mais saudável e às pressões do mercado para utilização de meios de produção mais sustentáveis (RODRIGUES et al., 2009).

Neste trabalho objetivou-se avaliar o efeito de cinco adubações orgânicas para o cultivo de rúcula, sendo utilizados esterco de coelho, suíno, aves, bovino e ovino.

\section{MATERIAL E MÉTODOS}

O experimento foi conduzido no município de Presidente Prudente/SP com a altitude de 430 metros, nas dependências da ETEC Prof. Dr. Antônio Eufrásio de Toledo, localizada a margem da Rodovia Raposo Tavares, KM 561. O clima da região, segundo a classificação de Koppen , é do tipo Cwa com temperatura média anual de $25 \circ \mathrm{C}$ e regime pluvial caracterizado por dois períodos distintos, um chuvoso de outubro a março e outro de baixo índice pluvial de abril a setembro.

A semeadura foi realizada no dia 24 de março de 2015, onde foram semeadas 2 bandejas com 200 células cada uma, nas quais foram utilizados $10 \mathrm{Kg}$ de substrato Bioplant ${ }^{\circledR}$ misturado com $2,5 \mathrm{Kg}$ de Yoorin e adicionado água quando necessário. Foram colocadas em média 7 a 8 sementes por célula, após essa etapa foram regadas e cobertas com uma lona de cor escura. As bandejas permaneceram nessas condições por um período de 3 dias, para permitir a germinação das sementes, sendo em seguida transferidas para a estufa.

A variedade de rúcula (Eruca sativa) utilizada foi a Selecta ${ }^{\oplus}$. As adubações foram realizadas em cinco tipos de esterco e uma testemunha, sendo assim divididos e denominados: suíno (Tratamento 1 - "T1"), coelho (Tratamento 2 - "T2"), aves (Tratamento 3 - "T3"), bovino (Tratamento 4 - "T4"), ovino (Tratamento 5 - "T5") e a testemunha (Tratamento 6 - "T6"). Os variados tipos de estercos foram obtidos na própria unidade, sendo que os mesmos foram 
coletados e pesados para a implantação, perfazendo uma média de $3 \mathrm{Kg}$ espalhados uniformemente em toda a extensão demarcada do canteiro e incorporados ao solo com o auxílio de um encanteirado acoplado a um trator.

Após a incorporação, o canteiro (dimensão de $24 \times 1 \mathrm{~m}$ ) permaneceu em repouso por 7 dias, para daí então ser realizado o transplante das mudas para o mesmo. O espaçamento utilizado foi de $20 \mathrm{~cm} \times 20 \mathrm{~cm}$, sendo divididos 3 metros de canteiro para cada adubação, com um espaçamento de 1 metro entre cada divisão. Após o período de 2 dias foram colocados palha seca, como fonte de cobertura morta entre as linhas.

Os canteiros foram adubados com torta de mamona da marca Vitaplan como fonte de nitrogênio, ácido bórico como adubação folhear e Dipel com a finalidade de conter pragas que já se encontravam presentes e as que por ventura viessem a surgir.

O local onde foi implantado o experimento dispõe de irrigação automatizada, sendo ativada 2 vezes ao dia, uma na parte da manhã e outra na parte da tarde, em um tempo médio de 15 a 20 minutos.

A colheita foi realizada no dia 12 maio de 2015, sendo coletados 20 pés de rúcula do centro do canteiro de cada tipo de adubação, determinando-se o peso total. As plantas foram lavadas e descartou-se aquelas não comercializáveis. O total das plantas coletadas foi pesado e desse total, pesaram-se separadamente a parte aérea e a parte radicular de 5 plantas escolhidas aleatoriamente, com auxílio de balança eletrônica.

Todos os dados foram submetidos à análise de variância (ANOVA, $p<0,05$ ) e ao teste de comparação de médias pelo teste Tukey $(p<0,05)$, segundo Silva (2011) e para a confecção dos gráficos foi utilizado o programa Excel.

\section{RESULTADOS}

Tabela 1. Resultados da produção de rúcula diferentes tipos de estercos. Presidente Prudente/SP Rúcula

\begin{tabular}{ccccccc}
\hline & $\begin{array}{c}\text { T1 (Esterco } \\
\text { Suíno) }\end{array}$ & $\begin{array}{c}\text { T2 (Esterco } \\
\text { Coelho) }\end{array}$ & $\begin{array}{c}\text { T3 (Esterco } \\
\text { Aves) }\end{array}$ & $\begin{array}{c}\text { T4 (Esterco } \\
\text { Bovinos) }\end{array}$ & $\begin{array}{c}\text { T5 (Esterco } \\
\text { Ovinos) }\end{array}$ & $\begin{array}{c}\text { T6 } \\
\text { (Testemunha) }\end{array}$ \\
\hline $\begin{array}{c}\text { Peso da } \\
\text { raiz }\left(\mathrm{g}^{-1}\right)\end{array}$ & $20,00 \mathrm{~b}$ & $40,00 \mathrm{a}$ & $15,00 \mathrm{c}$ & $15,00 \mathrm{c}$ & $20,00 \mathrm{~b}$ & $15,00 \mathrm{c}$ \\
\hline $\begin{array}{c}\text { Peso da } \\
\text { parte aérea } \\
\left(\mathrm{g}^{-1}\right)\end{array}$ & $375,00 \mathrm{c}$ & $770,00 \mathrm{a}$ & $225,00 \mathrm{e}$ & $370,00 \mathrm{c}$ & $480,00 \mathrm{~b}$ & $300,00 \mathrm{~d}$ \\
\hline $\begin{array}{c}\text { Peso total } \\
\left(\mathrm{kg}^{-1}\right)\end{array}$ & $395,00 \mathrm{c}$ & $810,00 \mathrm{a}$ & $240,00 \mathrm{e}$ & $385,00 \mathrm{c}$ & $500,00 \mathrm{~b}$ & $315,00 \mathrm{~d}$ \\
\hline
\end{tabular}

*Médias seguidas pela mesma letra não diferem significativamente entre si, segundo Teste de Tukey, a $5 \%$ de probabilidade (ASSISTAT). 


\section{DISCUSSÃO}

Através dos resultados obtidos neste experimento, verifica-se que dos cinco tipos de estercos aplicados (aves, bovino, coelho, ovino e suíno) pode se verificar que a utilização do esterco de coelho resultou em resposta significativa no desenvolvimento das plantas de rúcula em comparação aos demais estercos testados, tanto no parâmetro do peso total (dentre 20 amostras utilizadas), quanto nos pesos frescos da parte radicular e parte aérea.

O tratamento com esterco de aves não influenciou no crescimento das plantas de rúcula, sendo que alguns dos dados assemelham-se ao tratamento testemunha, onde não foi aplicado nenhum tipo de tratamento. Em relação aos pesos total e da parte aérea, o esterco de aves resultou em valores menores do que a testemunha. Já em relação ao sistema radicular, o esterco de aves se assemelhou ao esterco de bovinos e testemunha, mas mesmo assim mantiveram resultado menos satisfatório. Este padrão de resposta se deve possivelmente ao fato de que o solo já possuía um alto teor matéria orgânica e tinha recebido adubação verde, o que resultou em uma baixa resposta ao nitrogênio incorporado pelo esterco de aves. Para Oliveira et al. (2009), elevados teores de esterco podem descontrolar a função nutricional do solo, gerando assim um fator de redução e atrapalhando o desenvolvimento e produção final da cultura.

O estercos bovino e suíno apresentaram resultados semelhantes estatisticamente nas avaliações de peso total e parte aérea, diferenciando-se apenas na parte radicular da planta, onde o esterco suíno foi melhor, assemelhando-se nesse quesito ao esterco de ovinos.

O uso de diferentes tipos de estercos na mesma dosagem para a produção de rúcula, apresentou resultados diferentes, mas nenhum dos tipos de esterco conseguiu resultado tão satisfatório quanto o esterco de coelho nas condições deste experimento. Para Gurgel et. al. (2012), o uso do esterco de coelho e da cama de frango, quando utilizados como cobertura morta, favoreceu o desenvolvimento da planta em relação ao comprimento e peso fresco das folhas e do peso fresco das raízes de Brassica pekinnensis L. no cultivo orgânico.

\section{CONCLUSÃO}

O uso de esterco de coelho é viável para a produção orgânica de rúcula, proporcionando um maior equilíbrio entre o desenvolvimento da raiz e da parte aérea e resultando em um peso total satisfatório.

\section{REFERÊNCIAS}

CALEGARI, A. Espécies para cobertura do solo. In: In: DAROLT, MR (Coord.). Plantio direto: pequena propriedade sustentável. Londrina: IAPAR, 1998. p.65-94 
EMBRAPA/SEBRAE. Catálogo Brasileiro De Hortaliças: saiba como plantar e aproveitar 50 das espécies mais comercializadas no País. Brasília: EMBRAPA. 2010. 59p

FILGUEIRA, F.A.R. Novo manual de olericultura: agrotecnologia moderna na produção e comercialização de hortaliças. Viçosa, MG: UFV, 2000. 402p. p. 284-295

GURGEL , A. U. M. Efeito do uso de diferentes tipos de cobertura morta no cultivo orgânico de plantas de couve chinesa - Brassica pekinnensis L. var. Chouyou (TAKII seeds). E. Ciências Agrárias 1. Agronomia - 4. Fitotecnia. 64a Reunião Anual da SBPC São Luíz, MA: UFMA, 2012.

MAKISHIMA, N. O cultivo de hortaliças. Brasília: EMBRAPA-CNPH: EMBRAPA-SPI, 1993. (Coleção Plantar, 4)

Oliveira, F. de A.; Oliveira Filho, A. F.; Medeiros, J. F. de; Almeida Júnior, A. B.; Linhares, P. C. F. Desenvolvimento inicial da mamoeira sob diferentes fontes e doses de matéria orgânica. Revista Caatinga, v.22, p.206-211, 2009.

ROCHA IL. Novidades no Mercado de Frutas e Hortaliças Frescas. Hortibrasil, 2010.

RODRIGUES, R. R.; CARLOS, C. C.; MENDONÇA, P. S. M.; et al. Atitudes e fatores que influenciam o consumo de produtos orgânicos no varejo. REMark - Revista Brasileira de Marketing, São Paulo, v. 8, n. 1, p 164-186, jan./jun. 2009.

SEDIYAMA MAN; SALGADO LT; PINTO CLO. Rúcula. In: PAULSA JUNIOR TJ; VENZON, M. 101 Culturas: manual de tecnologias agrícolas. Belo Horizonte: Epamig. 683-686, 2007.

SILVA, E. C. F.; Produção de composto orgânico. 2008. 30 p. Trabalho de Conclusão do Curso de Tecnologia em Cafeicultura (Graduação). Escola Agrotécnica Federal de Muzambinho, Muzambinho, Muzambinho, 2008.

SILVA, F. de A. S. Assistat Software - Assistência Estatística. Versão 7.6 beta (2011). Disponível em http://www.assistat.com/indexp.html.

TEDESCO, M.J.; SELBACH, P.A.; GIANELLO, C., CAMARGO, F.A.O. Resíduos orgânicos no solo e os impactos no ambiente. In: SANTOS, G.A.; SILVA, L.S.; CANELLAS, L.P.; CAMARGO, F.A.O. Fundamentos da matéria orgânica do solo: ecossistemas tropicais e subtropicais. 2.ed. Porto Alegre: Metrópole, 2008. p.113-136. 